\title{
RESENHA: Foucault
}

\author{
Fernando Bertani Gomes \\ Grupo de Estudos Territoriais / UEPG - Brasil \\ ferbg28@gmail.com
}

Resenha: DELEUZE, Gilles. Foucault. $2^{\circ}$ ed. $2^{\circ}$ reimp. Buenos Aires: Paidós, 2008.

Esse livro é escrito por Gilles Deleuze (1925-1995) na forma de homenagem à morte precoce de Michel Foucault (1926-1984). Os pensadores franceses estabeleceram 0 primeiro encontro no ano de 1962 e desde então seguiram realizando trocas teóricas e admirações. Ainda que a obra leve o nome de Foucault é errado deduzir que se trata apenas de um escrito comentário sobre a vida e obra do homenageado, mais que isso o livro corresponde à posição apropriação de Deleuze em seus textos 'biográficos' ${ }^{1}$ e por meio deles compor sua própria filosofia, ou como ele mesmo definiu em uma entrevista, trata-se de praticar uma 'enrabada', fazendolhe um filho por trás e desse encontro fazer nascer um monstro, tornando-se indefinível os limites entre um e outro. Deleuze utiliza-se de obras selecionadas por ele como centrais que são 'A Arqueologia do Saber' (1969), 'Vigiar e Punir' (1975) e 'História da Sexualidade: O Uso dos Prazeres' (1984).

O livro é organizado em dois capítulos principais, sendo o primeiro dividido em duas seções que tratam respectivamente sobre arquivo e diagrama, correspondendo à forma com que Foucault elabora suas análises sobre saber e poder. O segundo capítulo está organizado em três seções que correspondem ao que Deleuze denominou de as três ontologias da obra de Foucault que seria os estros de saber, as estratégias de poder e os processos de subjetivação. Por fim a edição apresenta um anexo sobre a 'morte do homem' e o 'superhomem'.

A primeira seção, do primeiro capítulo, Deleuze preocupa-se em justificar porque
Foucault seria um tipo de 'novo arquivista'. Novo por se preocupar somente com os enunciados, diferentemente do que faz um arquivista antecedente que se atenta às proposições e frases. Frente às verticalidades das proposições e as lateralidades das frases um novo arquivista se posiciona diagonalmente preocupado em apreender aquilo que não se podia apreender.

Proposições e frases podem, entre si, contradizerem-se no momento em que para sua concepção é necessária a distinção entre o possível (virtual) e real, na medida em que no nível dos enunciados tudo é real. Tomando isso, a arqueologia estabelecida por Foucault não está preocupada em abstrações e contradições abundantes entre frases e proposições, mas porta-se como um corte (ou dobra) diagonal sobre os enunciados organizados hierarquicamente em níveis. Se enunciado significa a emissão de singularidades, essas estão em constante vínculo com seus espaços correspondentes de formação e transformação, é por meio desse espaço que se distribuem e se transformam.

Sobre um enunciado o autor ainda afirma não haver nenhum sujeito antecedente, antes está sempre localizado segundo o qual se conserva, transmite ou repete, seu sentido não é estabelecido mediante um significante, mas sua regularidade ou não com o espaço, elemento este que será aludido posteriormente na discussão sobre Foucault e sua adjeção com uma nova cartografia.

Deleuze propõe a sistematização de três espaços para os enunciados: 'espaço lateral': formado por um conjunto de relações entre 
enunciados, ressaltando a impossibilidade de existência de um espaço homogêneo insensível aos enunciados como também a indisposição de haver enunciados não localizados; por segundo o 'espaço correlativo': que trata da relação dos enunciados com os sujeitos diferentemente de uma análise sobre o sujeito de uma frase, as proposições sistematizadas em uma frase remetem à um sujeito conector intrínseco, já os enunciados são constituídos de uma variável intrínseca ao próprio enunciado, aquilo que Deleuze denomina em Foucault enquanto um enunciado sonho, diferente de um sistema de palavras que procedem de uma variável interna/externa, os enunciados produzem variáveis inerentes a sua própria natureza de multiplicidade e possibilidade de fazer surgir o novo, premissa que reforça o projeto filosófico - se é que o autor tenha projetos, da diferença de Deleuze; por fim o 'espaço complementar': responsável pelas formações não discursivas que $o$ autor estabelece uma terceira via de acesso à relação entre as formações discursivas e as instituições produzidas concomitantemente, toda instituição implica enunciados e todo enunciado é produzido localmente, por meio de uma multiplicidade de enunciados arranjados que toma na filosofia de Foucault o nome de dispositivo.

A segunda parte, do primeiro capítulo, Deleuze vai tratar do adjetivo logrado por Foucault em ser 'um novo cartógrafo'. Por posições tomadas em consequência da apropriação da obra de Foucault, Gilles Deleuze prioriza como centrais em sua biografia os escritos de 'A Arqueologia do Saber' (1969) e 'Vigiar e Punir' (1975) livros estes que marcam, segundo o autor, a mudança de foco de Foucault do saber para o poder. $\mathrm{O}$ enunciado, segundo a sentença de Deleuze, é em si mesmo repetição, sendo essa repetição responsável por animá-lo, entretanto, os limites do saber estão entremeados por algo que seja quase idêntico, mas que antecipadamente é responsável por fazer repeti-lo: eis o poder.

Nesse momento do livro, Deleuze concede a posição de um novo cartógrafo por considerar que Michel Foucault, utilizando da história em suas análises, antes de tudo era um filósofo e por vezes, um poeta. Sendo um arqueólogo não via as escrituras como um fim, mas detinha uma capacidade de elaborar quadros como pano de fundo de suas análises microfísicas que, para Deleuze, são capazes de delinear os efeitos de um fenômeno, num sentido ótico através de cores, por exemplo, a cor vermelha que estampam os suplícios ou cinza das prisões. Com influências de suas obras sobre o pintor francês Francis Bacon, Deleuze recompõe o que denomina de 'diagrama', que na obra ele traz algumas características implícitas ao conceito: definindo primariamente enquanto uma multiplicidade espaço-temporal; extremamente fluído e instável, portanto, está sempre em mutação; tendo a necessidade de configurá-lo como um corte intersocial em devir, criando realidade e de maneira alguma sendo um modelo de representação da realidade. Sobretudo, nesse momento é que Deleuze sublinha e sublima as contribuições de Foucault com as análises sobre poder, que emergem de maneira pertinente em um momento, afirma ele, dominada por um tipo de marxismo acadêmico e esquerdismo que compreendiam o poder enquanto uma substância conquistada por uma classe específica e, sendo assim. Deveria ser tomada por meio de embates totalizantes, ao modo que o 'novo cartógrafo' propunha um poder não na forma de uma propriedade de posse, mas de práticas estratégicas na forma de táticas, manobras e técnicas, portanto, compostas por um relevo que possibilita conexões e convergências.

Reafirmando a filosofia da diferença do autor, o livro segue como um ritornelo ${ }^{2}$, 
manifestando um encontro de um 'eu' com um 'outro' que entre si se transmutam e sob essa premissa que Deleuze cria alguns paralelismos conceituais com seu conterrâneo, como as relações de poder de Foucault semelhantes às 'máquinas abstratas' ou 'agenciamentos abstratos' de Deleuze ou a aproximação do seu conceito de 'agenciamentos concretos', que segundo ele, na obra de Foucault tomava o nome de 'dispositivo', enquanto uma rede, de pontos de encontros que formatam e dão forma a uma 'máquina abstrata' que funciona como um plano de imanência que atualiza, integra e diferencia um quadro social. Ou na linguagem de Foucault, dispositivos são um conjunto de instituições, táticas e estratégicas que dão continuidade a uma dinâmica social estando esse dispositivo sempre em conformidade com as relações de poder engendradas nas diferentes instâncias sociais, como o 'panoptismo' trabalhado em 'Vigiar e Punir' (1975) responsável por regular a 'sociedade disciplinar'.

O segundo capítulo da obra está organizado em três momentos que correspondem a três questões que Deleuze afirma serem os sulcos por onde correm os rios das análises históricas de Michel Foucault: 'o que sei?'; 'o que posso?' e 'o que sou?'.

A primeira questão corresponde aos estudos históricos de Foucault sobre o saber, o autor traz a noção dos 'estratos do saber' que são como camadas sedimentares ${ }^{3}$ de coisas e palavras que conferem dois elementos bastante caros na escrita do livro: luminosidade e legibilidade, a primeira refere-se às visibilidades, ou capacidade de fazer ver e ser visto, exemplo são os aparatos arquitetônicos da prisão para a disciplinarização dos corpos, a legibilidade trata dos enunciados e a capacidade de dizer e ser compreendido, um exemplo é a categoria de 'delinquente', figura central para a legitimação de práticas disciplinadoras. $\mathrm{Na}$ primeira seção, do segundo capítulo, baseada na primeira questão, Deleuze segue preocupado em delinear mais características dos dois elementos dos estratos do saber, o enunciado tem a virtude de ser espontâneo, por meio da linguagem, portanto determinante, enquanto que a visibilidade é sempre receptiva tomando a forma dos determinantes.

'O que posso?' corresponde à preocupação que Foucault teve em compreender em quê consiste o poder que, segundo Deleuze, é estabelecido como uma relação de forças que por sua vez compõe as tão evocadas relações de poder. Nessa seção, o objetivo é delimitar as características do poder, uma delas é que é sempre uma relação, portanto, não é emanado de uma forma, como a forma-Estado, sendo relação nunca é singular. Outra característica bastante cara para Deleuze, corresponde ao adjetivo 'o novo cartógrafo': o poder é sempre local e nunca global, todavia, não localizável por ser difuso. São categorias do poder: incitar, induzir, desviar, facilitar ou dificultar, ampliar ou limitar, fazer o mais ou menos provável, destarte, o poder possui, conforme Deleuze afirma espontaneidade e receptividade ou capacidade de afetar e ser afetado, e está sempre em cumplicidade com os estratos do saber, não sendo ele estratificado, mas estratégico, da ordem do devir, responsável por atualizar as estratificações conferindo-lhes continuidade ou conflito. Gilles Deleuze retoma, nesse momento, o conceito de 'diagrama' como uma prática de análise efetivada por Foucault e responsável por elucidar e afetar os efeitos das dinâmicas sociais, longe de elaborar um modelo representativo da realidade $o$ diagrama emite singularidades correspondendo à asseguração sumária de Deleuze de 'pensar de outra maneira'.

A terceira, e última seção, relaciona-se a questão de 'quem sou?' fechando os três 
momentos da obra de Michel Foucault que segundo Deleuze resumem sua pergunta central análoga a questão principal de filosofia de Immanuel Kant (1724-1804) que é 'o que é pensar?'. Nesse momento da obra, o autor aproxima-se das últimas investigações de Foucault em 'O uso dos prazeres' (1984) sobre os gregos.

De maneira geral, Deleuze empenha-se em delinear o caráter ontológico da obra de Foucault delimitando três características vinculadas ao ato de pensar: primeiramente pensar é ver e falar; têm relação com o fora; e consiste em uma dobra desse fora, tornandose um dentro, eis o processo de subjetivação. A compreensão do que seria 'o fora' deve ser tomada com as outras escalas de análise, assim como Foucault um dia adiantou-se em afirmar que os estratos do saber são atualizados pelas relações de poder, também elabora um deslocamento analítico quando afirma não ser o poder uma clausura. Se tudo provém de relações de poder, seria impossível então 'escapar' disso? Nesse sentido, nem o saber é determinístico pelas relações entre seus estratos, por serem eles resultantes de relações difusas de forças que compõe as relações de poder, estas compostas como um fora (dehors), como aquilo que o pensamento não pensa, como impensável, porém responsáveis por constituir um dentro (dedans), gerados por movimentos oscilantes e como afirma Deleuze, peristálticos, que são as dobras, dobramentos, subjetivações. As dobras ressaltadas na obra de Foucault têm forma de atos de resistência, ou seja, fazem vergar as relações de força de modo que afetam a si mesmas, através desses atos de resistências que conforme as análises históricas de Foucault, os gregos efetuavam a relação consigo através da sexualidade e do uso dos prazeres.

Nesse momento final do livro, o autor segue demonstrando as semelhanças entre as 'dobras' de Maurice Merleau-Ponty (1908-
1961) e Martin Heidegger (1889-1976), contudo, afirmando as singularidades do pensamento de Foucault que se distingue por compreender 'o dentro' como expressão de um 'ser-saber', distribuído entre 'ser-luz' e 'ser-linguagem', mas que não deixa de ser uma dobra do fora, portanto, há aí uma relação topológica que posiciona a relação consigo mesmo (ou a subjetivação) como sendo homóloga a relação com o fora,. Nesse diagrama, pensar não é algo inato que revela um mundo exterior, como legisla a filosofia de base platônica, pensar torna-se algo adquirido que por meio de uma relação com 'o fora' o torna íntimo, por isso Deleuze evoca Antonin Artaud (1896-1948) para afirmar que o pensamento é genital e essa genitalidade confere a qualquer indivíduo a possibilidade de produzir singularidades de resistência, uma vez que são íntimos 'do fora'

A publicação utilizada para essa resenha é finalizada com um anexo que corresponde a um texto que Deleuze faz uma aproximação entre as evocações da morte do homem em Foucault e a ideia de 'superhomem' de Friedrich Nietzsche (1844-1900) como reflexões para pensar um além do homem, ou uma nova possibilidade de pensar os corpos viventes a despeito de todo projeto humanista para as virtudes racionais da entidade denominada 'homem'. Como sugestão apresenta o que seria uma 'sobredobra' como desapropriações repetidas infinitas vezes. Essa noção corresponde aos escritos de Deleuze sobre o filósofo alemão Nietzsche que compôs a ideia do 'eterno retorno', que para Deleuze não seria um eterno retorno do mesmo, mas do diferente, dessa forma, uma 'sobredobra' é semelhante ao sujeito ético de Foucault que preocupado com o cuidado de si, toma posições de resistência e criação mediante as homogeneidades do saber. Filiarse tão somente às luzes e enunciados do saber é dar continuidade a eles, enquanto que aqueles vergam os limites do pensável abrem 
possibilidade para o novo.

O livro de Deleuze homenageando Foucault proporciona um encontro singular que faz emergir formulações teóricas que correspondem aos escritos de cada um, mas que isolados não fariam produzir as singularidades presentes nesse encontro de semelhanças e diferenças. Alguns conceitos reatualizados como o 'diagrama' de Deleuze referente às 'genealogias do poder' de Focault ou os 'estratos do saber' referente às 'arqueologias do saber', dão às análises históricas de Foucault uma linguagem demasiado espacial. Nesse sentido, o livro torna-se fundamental para discussões geográficas atuais que embora, por vezes, tenha sido deixado de lado por não ter em seu título um chamariz bastante comum que é a palavra 'espaço' seguido de algum adjetivo. Esta obra tem a capacidade de tornar insustentável a compreensão do presente tendo como pano de fundo a noção de um espaço isonômico ou como síntese totalizante dos fenômenos sociais. 